\title{
Title: Epigenetic regulation during mammalian oogenesis
}

John Bromfield ${ }^{1,2}$, Will Messamore ${ }^{1,2}$ and David F. Albertini ${ }^{1,2,3}$

${ }^{1}$ Department of Molecular and Integrative Physiology

${ }^{2}$ The Center for Reproductive Sciences, University of Kansas Medical Center, Kansas

City, KS 66160

${ }^{3}$ Marine Biological Laboratory, Woods Hole, MA 02543

Keywords: methylation, developmental programming, embryogenesis, assisted reproductive technique.

Corresponding author:

David Albertini

3901 Rainbow Boulevard

University of Kansas Medical Center

Kansas City, KS 66160

Phone: 916-588-4012

Fax: 916-588-0456

Email: dalbertini@kumc.edu 


\begin{abstract}
The advent of the epigenetic era has sparked a new frontier in molecular research and the understanding of how development can be regulated beyond direct alterations of the genome. Thus far, the focal point of epigenetic regulation during development has been chromatin modifications that control differential gene expression by DNA methylation and histone alterations. But what of events that alter gene expression without direct influence on the DNA itself? This review focuses on epigenetic pathways regulating development from oogenesis to organogenesis and back that do not involve methylation of cytosine in DNA. We discuss target components of epigenetic modification such as organelle development, compartmentalization of maternal factors and molecular mediators in the oocyte and how these factors acting during oogenesis impact on later development. Epigenetic regulation of development, be it via cytosine methylation or not, has wide ranging effects on the subsequent success of a pregnancy and the intrinsic health of offspring. Perturbations in epigenetic regulation have been clearly associated with disease states in adult offspring including type II diabetes, hypertension, cancers and infertility. A clear understanding of all epigenetic mechanisms is paramount when considering the increased utilization of assisted reproductive techniques and the risks associated with their use.
\end{abstract}

\title{
Introduction
}

(The notion that the fertilized egg and its subsequent development rely upon the imposition of competencies during oogenesis has been emphasized. At the genetic level, a host of genes and their protein products have been implicated in post-fertilization success of mammalian embryos. In some cases, these gene products are either stored as mRNAs, microRNAs, or as proteins that linger zygotically for varying amounts of time only to be called into action at a specific developmental transition to sustain embryonic progression. Such products are often referred to as those of maternal effector genes as they represent female germ line entities that are critical for embryogenesis. In addition to the ever growing list of oocyte genes that are involved in development of oocytes, follicles or embryos, a number of epigenetic factors have been identified that play 
perhaps even more central roles in establishing and maintaining pregnancies resulting in the birth of healthy offspring.

Epigenetics has emerged as a fascinating field within developmental biology as evidenced when the absence of a specific gene or its protein product cannot adequately address frank embryonic/fetal loss or functional impairments apparent in neonates or adults. In 1942 Conrad Waddington first coined the term epigenetics as "the branch of biology which studies the casual interactions between genes and their products." (Waddington, 1942) Simply stated for the purposes of this review, epigenetics involves molecular and cellular modifications required during early development that are truly independent of detectable changes in a gene's structure or function, a phenotypic change in the absence of a genotypic change. Thus, the networks of cell behaviors elicited during normal development, including metabolic, signaling, and protein interactive events must reflect patterns of cell organization laid down in the egg during oogenesis. There can be little doubt that the epigenetic factors elaborated during oogenesis operate and carry out their functions in collaboration with activities and entities that result from activation of the zygotic genome. But for the purposes of this review, we will focus on true oogenetic determinants whose functions have been primarily gleaned from studies on mice. For this reason, only generally accepted parallels in domesticated species and in humans will be drawn upon. Additionally, our emphasis will be on the periods of greatest sensitivity during oogenesis where impairment of epigenetics will have dire consequences on either pregnancy success or offspring health status. Thus, the notion that perturbation of events at critical junctures during oogenesis impact in lethal or non-lethal ways on the embryo, fetus, or neonate will be offered to provide new direction for understanding the causes of maternal aging on fecundity as well as possible mechanisms whereby the epigenetic competence of an embryo can be traced back to intraovarian events at various stages of the life cycle. This latter topic is especially relevant to mounting concerns in the arena of assisted reproductive technology (ART).

\section{The epigenetic egg - thinking beyond oogenesis}


While the emphasis of this review is focused toward understanding the epigenetic mechanisms that may be occurring during oogenesis and ultimately impacting on embryo development and post-natal health, a concise review of these mechanisms would not be complete without consideration to the research focused on epigenetic mechanisms affecting the zygote during the post-fertilization period.

The earliest of studies defining post-fertilization effects on post-natal development focused on a cohort of individuals who underwent gestation during the Dutch famine during World War II. Extensive medical records during this time allowed researchers some fifty years later to identify individuals whose mothers suffered caloric restriction during one of the three trimesters of pregnancy (Elias et al. 2004; Elias et al. 2005; Elias et al. 2005; Roseboom et al. 2001). Many of these retrospective studies have been able to demonstrate a link between these periods of caloric restriction and specific predispositions to disease states during adulthood, particularly, but not restricted to, those of a metabolic nature including type II diabetes, hypertension and obesity (Roseboom et al. 2001). The majority of these studies did not specifically identify epigenetic modifications as a cause of the phenotypes witnessed in many of these individuals, but it is difficult to perceive another mechanism that could be responsible. Predominately these effects have been associated with a programming of the fetuses own metabolic pathways in response to the environment to which it's mother is being exposed, to ready the fetus for the ensuing environment in which it must survive (Hales and Barker 2001). Since these earlier studies, many groups have undertaken research strategies to identify particular pathways in which this programming may occur in a post-fertilization setting (Table 1). Many groups have persisted with using various models of caloric restriction in animal models, altering the nutritional value of the maternal diet (high caloric, low protein/isocaloric), and of greater interest, the time and duration in which these actions occur. It has been demonstrated that a isocaloric/low protein diet during the periimplantation or peri-ovulatory period can drive the development of obesity and early onset hypertension in subsequent offspring, the latter (peri-ovulatory) implicating that even the final stages of meiotic maturation may be affected by as little as an $8 \%$ reduction 
maternal protein consumption for only three days prior to ovulation (Kwong et al. 2000; Watkins et al. 2007).

Since the 1960's dietary folate intake during and prior to pregnancy has been associated with establishing and maintaining a healthy pregnancy (Lowenstein et al. 1966). More recently Van Engeland et al. have demonstrated that enzymes involved in methylation and demethylation of the genome during epigenetic imprinting are regulated by folate intake and availability, suggesting that maternal diet may directly influence epigenetic programming of the conceptus during development (van Engeland et al. 2003). In addition, it has been shown that in mice methyl dietary supplements can alter methylation of specific imprinted genes (Cooney et al. 2002). Although these dietary and nutritional restriction models are invaluable for understanding the development of adult disease, they are yet to lead to elucidation of the epigenetic pathways leading to these and other etiologies.

The advent of the epigenetic era in conjunction with available molecular and microscopy technologies has allowed researchers to begin to determine some of the biochemical and cellular pathways leading to anomalous epigenetic modifications during development. It is believed that any manipulation or adverse effect to the oocyte or zygote will drive compensatory cellular responses, ultimately leading to alterations in gene expression during early development. Alterations in gene expression may arise from either changes in direct epigenetic programming of the egg, or alternatively through changes in transcriptional activity. These observations have clearly been demonstrated using in vitro produced embryos where culture conditions lead to altered patterns of gene expression (Niemann and Wrenzycki 2000). Differential methylation of the genome has also been demonstrated as a result of in vitro embryo culture, showing a clear susceptibility of the conceptus to epigenetic reprogramming at this time (Khosla et al. 2001; Young et al. 2001). Embryo promoting factors, including growth factors or buffering agents have also been used in in vitro culture to aid in embryonic development and survival. Rinaudo and Schultz, using a micro array approach, demonstrated that even alteration in culture media composition can change global gene expression patterns in the embryo (Rinaudo and 
Schultz 2004; Rinaudo et al. 2006). This work has aided in the development of culture media supplemented with exogenous embryo promoting factors and buffering agents to support embryonic development under conditions that better reflect the in vivo developmental environment. This reinforces the notion of a more Lamarckian evolutionary principle since environmental conditions lead to marked changes in gene expression during mammalian development.

Any stressor affecting the embryo during development may influence gene expression and therefore alter the developmental competence of the embryo. Changes in intracellular REDOX state have been shown to alter expression of oxygen sensitive genes (Harvey et al. 2007), while environmental toxin exposure has been shown to alter gene expression and embryonic developmental competence (Susiarjo et al. 2007). Ammonia accumulation within in vitro culture media can again lead to perturbed embryonic developmental competence via altered gene expression (Lane and Gardner 2003). Changes in organelle number and distribution have been associated with stressors during development. Mitochondrial DNA is derived solely from the maternal genome and is replicated for only a very short period following fertilization, suggesting a very short period when external factors can influence mitochondrial number. Mitochondrial number and function have been shown to be altered in embryos following either altered maternal protein consumption or in vitro embryo culture and are maintained beyond post-natal development (McConnell and Petrie 2004; Taylor et al. 2005). Perturbations to embryonic development due to in vitro culture have demonstrated imbalances in the allocation of blastomeres between inner cell mass and trophectoderm cell lineages (Lee et al. 2004). In this light, embryo culture has been shown to alter placental morphology and function (Sjoblom et al. 2005). In addition, placental insufficiencies adversely affect fetal development, including the on-set of adult disease (Anderson et al. 2006; Hayashi and Dorko 1988). Early alterations in gene expression, particularly of imprinted genes may be a key driving force in perturbing placental development and function, resulting in altered fetal development, and may impact blastomere fate allocation during earlier development. A number of imprinted genes have now been identified, many of which have direct roles in placental development (Coan et al. 2005). 
Children arising from in vitro embryo culture have been shown to have altered birth weights, which have been the most historical epidemiological link in the onset of adult metabolic diseases (reviewed in Barker (Barker 1998)). Approximately 2-3\% of the national birth rate of many western countries is comprised of babies born from assisted reproductive techniques (ART), resulting in babies of an increased incidence of pre-term birth, lower birth weight for gestational age and some suggestion of increased birth defects. Imprinting disorders such as Angelman and Beckwith-Wiedemann syndromes have also been closely associated with babies derived from ART, suggesting that improper imprinting which occurs to the embryo as result of in vitro culture may be the penultimate cause for the disposition to these syndromes (Cox et al. 2002; DeBaun et al. 2003; Maher et al. 2003; Orstavik et al. 2003).

The links between the pre- and post-fertilization events which impact the epigenetic programming responsible for altered development post-natally have yet to be clearly defined. However, the accumulation of evidence from epidemiological, in vitro and ex vivo culture in addition to many observational studies defining actions resulting in perturbations at any stage of development are now beginning to demonstrate a process of epigenetic re-programming throughout development from oogenesis, organogenesis and back. The recent demonstration of the trans-generational effects of environmental stressors (Skinner 2007) is evidence of the continuum of susceptibility from oogenesis throughout development; this is of particular relevance when considering the foundation for the next generation and its establishment in the oocyte during gestation.

\section{Epigenetic principles governing oocyte development.}

There are many generally acknowledged features of the mammalian oocyte that link basic architectural aspects of egg design to the more immediate consequences apparent in the pre-implantation embryo. Before reviewing these, it is important to point out that the production of epigenetically competent oocytes is a by-product of the germ cell's life history within the ovary. The coordination of folliculogenesis with oogenesis clearly 
requires a balance of cellular interactions between the ovarian somatic components and the oocyte and the feedback interactions that are mediated by hormones and growth factors within the hypothalamic-pituitary-gonadal axis (Combelles et al. 2004). How circadian rhythms participate in this complex multicellular dialogue is only now being uncovered (Karman and Tischkau 2006) and is beyond the purview of this paper. Many elements of these feedback mechanisms are resolved, but suffice it to say that disturbances in somatic physiology are likely to impact the epigenetic quality of oocytes depending on the stages of oogenesis that are at risk during fetal, prepubertal, or adult phases of the life cycle.

Amongst the hallmarks of oocytes that successfully complete oogenesis are those that relate to specific post-fertilization functions in the egg (Table 2). Thus, the elaboration of the zona pellucida illustrates one of the earliest structures that will ultimately present a substrate for interaction with sperm and cumulus cells. Similarly, the hypertrophic growth of the mammalian oocyte requires reduplication of most intracellular organelles such as mitochondria, Golgi complex, lysosomes and endoplasmic reticulum not only for sustaining adequate levels of protein synthesis but the sequestration of calcium within vesicles that are invoked at fertilization. That the germinal vesicle is modified at the level of chromatin patterning has been studied in many mammals, and generally these alterations in the location and extent of heterochromatization are linked to timely changes in transcription that assure large scale repression prior to fertilization. Interestingly, it is at the later stages of oocyte growth that heterochromatization is initiated, a time when both oocyte imprints are established (Obata and Kono 2002) and hormone regulated oocyte-granulosa interactions are diminished (Combelles et al. 2004). Finally, while often overlooked, a large degree of cortical differentiation is required in the oocyte for its successful transition into embryogenesis. Multiple Golgi complexes mediate the synthesis and packaging of the cortical granule contents and the cortical granules themselves must adopt a subplasmalemmal position in spatial compliance with the calcium sequestering vesicles alluded to earlier. When combined with the deployment of microvilli, and the dynamic web of actin filaments that will mediate cytokinesis during both polar body extrusion as well as blastomere cleavage, this complex network is likely to be central to 
protein localization for prolonging the lifespan of maternal gene products well into embryogenesis (see example of dMNT1 or below). Thus careful positioning of both organellar components, including the germinal vesicle, and components of the cytoskeleton represents the macromolecular outcome of oogenesis. That additional cytoskeletal and extracellular signals modulate this cortical differentiation observed in mammalian oocytes has also been proposed (Albertini and Carabatsos 1998).

On a more subtle level, but equally important in terms of epigenetic regulation, molecular mediators have been identified in many systems that function to render key catabolic, metabolic, or signaling pathways functional or not. A few examples relevant to oocyte epigenetics are listed in Table 3. As will be considered below, many factors that regulate key transition points in the cell cycle assume non-random localization in order to generate rapid and complete effects, assuring synchronization of kinase activation with timely ubiquitinization at, respectively, M-phase cell cycle entry or exit. Regulating cytoplasmic access is accomplished by nucleolar sequestration in yeast (Carmo-Fonseca et al. 2000). Centrosomes, in contrast, function to limit the diffusional capacity of the many components involved with cell cycle progression by complexing these factors to motor molecules that target and maintain their presence at microtubule organizing centers (MTOCs). Finally, the spindle itself serves to harbor and stabilize many factors that are involved in the timely degradation of cyclins that elicits the metaphase -anaphase transition during $\mathrm{M}$ phase. Collectively then, the emerging concept that through specific interactions with the cytoskeleton and other organelles, mRNAs and proteins can be localized, stabilized and/or rendered available for activating post-translational modification or gaining access to the nuclear compartment deserves consideration in the context of oocyte epigenetics. In fact, provocative findings suggest this to be an important element of egg design with immediate relevance to embryogenesis.

One of the first examples of the importance of protein localization during mouse development came from the studies of Ratnam et al., (Ratnam et al. 2002). They characterized an oocyte-specific splicing variant of the dimethyltransferase 1 gene, known as Dmnt1o, and showed that knocking out this gene resulted in arrest of 
development at the morula stage; a time that would coincide with the remethylation of male and female genomes. One possibility was that the mRNA for this protein was stored for regulated translation at this stage. Instead it was found that the mRNA was translated during the growth phase of oogenesis and the protein product was localized in the oocyte cortex where it remained until the 8 cell stage; at this point Dmntlo moved into the nucleus where it affected its chromatin modifying activity. Interestingly, another variant of Dmnt1 was also translated during oogenesis and served to methylate maternal imprints but was degraded once this was accomplished (see Table 3). These elegant studies illustrate several important epigenetic principles: that protein localization ensures functional activity and protection from degradation and prevents premature nuclear localization. This mechanism for regulating nuclear access is also likely to underscore the regulation of the meiotic cell cycle in oocytes because, as mentioned earlier, catalytic events that must be coordinated temporally are often spatially segregated in order to limit spurious activation during meiotic resumption (Albertini and Carabatsos 1998; Mitra and Schultz 1996).

There is a growing list of epigenetic regulators that impact the completion of meiosis, the transition into the embryonic mitotic cell cycle, and subsequent events related to morphogenesis and chromatin remodeling (Table 3). While this list is not comprehensive, it does serve to illustrate how the chronological readout of oocyte specific gene products dictates key transition points in early embryogenesis and the importance of mRNA or protein processing well after transcription has occurred. For example, cMOS has long been known to effect the block in the meiotic cell cycle at metaphase 2 in mammalian oocytes (Colledge et al. 1994). In mice, the relevant knockout phenotypes have documented and in the case of cMOS, its elimination results in the unregulated transition from meiosis to mitosis that causes parthenogenetic activation of the egg. Nucleoplasmin 2 (NPM2) causes arrest at the 1-cell stage due to impairment of pronuclear apposition (Burns et al. 2003). Expectedly, some maternal effect genes disrupt compaction, the process during which inner cell mass and trophectoderm allocation takes place as outer cells acquire the properties of a polarized epithelium (Selwood and Johnson 2006). These include E-cadherin, a protein essential for altering blastomere adhesive properties that 
result from the insertion of cytoplasmic protein into the blastomere plasma membrane (Selwood and Johnson 2006) and gamma tubulin. Gamma-tubulin is a key regulator of microtubule assembly due to its localization to the centrosome. GT1 is an ubiquitous variant that if deleted results in the arrest of embryos at the time of compaction (YubaKubo et al. 2005). While these embryos do proceed to compact, they are unable to progress through the cell cycle due to the role GT1 plays in the centrosome to harbor and regulate the activation of cdk1/cyclin complexes. The fact that zygotic gene activation coincides with the massive depletion of maternal mRNAs serves to emphasize what may be a general rule for epigenetic control of early development: oocyte gene products as proteins are better served to effect their regulatory activities than their respective mRNAs due to mechanisms that allow for their selective localization and protection from degradation. It will be interesting to determine if such mechanisms are operative in eggs of other mammalian species where current emphasis has been placed on mRNA displays rather than protein products. In this light, recent work on mouse oocytes has documented a role for tyrosine kinases in the regulation of the first embryonic cell cycle and here too, components of the signaling machinery for pathway exhibit distinct patterns of localization to both the spindle and the cell cortex (McGinnis et al. 2007).

In summary, this section has illustrated the importance of spatial localization as documented in the experimentally tractable murine model system. The success of a zygote is contingent on the zygote's ability to sequester and stabilize maternal effector genes as mRNAs, microRNAs or proteins, as well as, the zygote's ability to recruit these effectors for embryonic progression at proper timepoints. Thus establishing and maintaining positional information is likely to be regulated by cytoskeletal elements within the zygote. Future studies will be needed to assess the relative roles of nuclear cytoplasmic transport, cortical binding, and cytoskeletal interactions that may dictate the properties of stability and spatial patterning relevant to the early stages of development in mammals.

\section{Future directions}


The concept of an epigenetically competent oocyte has been introduced to explain how the design of the mammalian oocyte impacts directly on the post-fertilization development of the conceptus independent of zygotic gene regulation. How these regulatory principles are modified by environmental factors is not understood but two areas in reproductive biology seem to be likely targets for study in this vein. The widespread use of ARTs in animals and humans often draws attention to the epigenetic burdens that are placed on gametes and embryos that may affect the viability and health of offspring produced with these technologies. Chromatin remodeling, as noted earlier, is often cited as a cause for developmental failures, and in most cases defects in DNA methylation have been identified as a contributing factor. It remains, however, to be discriminately shown what mechanistic defects underlie inappropriate imprinting. Perhaps, with new technologies that would allow for an assessment of the dynamic nature of chromatin remodeling factors, new insights of relevance to improvements in ARTs will be obtained.

A second area of active investigation is the problem of reproductive aging in the practice of human ARTs. Current models to explain defects in oocytes that underlie age-related pregnancy loss and congenital defects focus on the status of oocyte chromatin during oogenesis and the impact that chiasma or telomeres may have on the processes of chromosome segregation prior to and after fertilization (Susiarjo et al. 2007). It seems equally relevant to consider that gradual changes in lifestyle, environmental exposure, and hormonal imbalance target aspects of the epigenetic regulation in the oocyte that bear directly on compromised developmental competence. These prospects are already being realized and are indicating that many steps during oogenesis may be at risk to modifications in epigenetic programming that will have long term consequences to offspring health. Realizing the imperative to expand research in this area will advance the quality of life in humans and animals for years to come.

\section{Acknowledgements}


We thank members of the Albertini lab for their support and advice and recognize the NIH (HD42076), ESHE Fund and the Hall Family Foundation for their generous support.

\section{References}

Albertini DF, Carabatsos MJ (1998) Comparative aspects of meiotic cell cycle control in mammals. J Mol Med 76, 795-9.

Anderson CM, Lopez F, Zimmer A, Benoit JN (2006) Placental insufficiency leads to developmental hypertension and mesenteric artery dysfunction in two generations of Sprague-Dawley rat offspring. Biol Reprod 74, 538-44.

Barker DJ (1998) 'Mothers, Babies and Health in Later Life.' (Churchill Livingstone: Edinburgh, NY)

Burns KH, Viveiros MM, Ren Y, Wang P, DeMayo FJ, Frail DE, Eppig JJ, Matzuk MM (2003) Roles of NPM2 in chromatin and nucleolar organization in oocytes and embryos. Science 300, 633-6.

Carmo-Fonseca M, Mendes-Soares L, Campos I (2000) To be or not to be in the nucleolus. Nat Cell Biol 2, E107-12.

Coan PM, Burton GJ, Ferguson-Smith AC (2005) Imprinted genes in the placenta--a review. Placenta 26 Suppl A, S10-20.

Colledge WH, Carlton MB, Udy GB, Evans MJ (1994) Disruption of c-mos causes parthenogenetic development of unfertilized mouse eggs. Nature 370, 65-8.

Combelles CM, Carabatsos MJ, Kumar TR, Matzuk MM, Albertini DF (2004) Hormonal control of somatic cell oocyte interactions during ovarian follicle development. Mol Reprod Dev 69, 347-55.

Cooney CA, Dave AA, Wolff GL (2002) Maternal methyl supplements in mice affect epigenetic variation and DNA methylation of offspring. $J$ Nutr 132, 2393S-2400S.

Cox GF, Burger J, Lip V, Mau UA, Sperling K, Wu BL, Horsthemke B (2002) Intracytoplasmic sperm injection may increase the risk of imprinting defects. Am J Hum Genet 71, 162-4.

DeBaun MR, Niemitz EL, Feinberg AP (2003) Association of in vitro fertilization with Beckwith-Wiedemann syndrome and epigenetic alterations of LIT1 and H19. Am J Hum Genet 72, 156-60. 
Elias SG, Peeters PH, Grobbee DE, van Noord PA (2004) Breast cancer risk after caloric restriction during the 1944-1945 Dutch famine. J Natl Cancer Inst 96, 539-46.

Elias SG, Peeters PH, Grobbee DE, van Noord PA (2005) The 1944-1945 Dutch famine and subsequent overall cancer incidence. Cancer Epidemiol Biomarkers Prev 14, 1981-5.

Elias SG, van Noord PA, Peeters PH, den Tonkelaar I, Grobbee DE (2005) Childhood exposure to the 1944-1945 Dutch famine and subsequent female reproductive function. Hum Reprod 20, 2483-8.

Hales CN, Barker DJ (2001) The thrifty phenotype hypothesis. Br Med Bull 60, 5-20.

Harvey AJ, Kind KL, Thompson JG (2007) Regulation of gene expression in bovine blastocysts in response to oxygen and the iron chelator desferrioxamine. Biol Reprod 77, 93-101.

Hayashi TT, Dorko ME (1988) A rat model for the study of intrauterine growth retardation. Am J Obstet Gynecol 158, 1203-7.

Karman BN, Tischkau SA (2006) Circadian clock gene expression in the ovary: Effects of luteinizing hormone. Biol Reprod 75, 624-32.

Khosla S, Dean W, Brown D, Reik W, Feil R (2001) Culture of preimplantation mouse embryos affects fetal development and the expression of imprinted genes. Biol Reprod 64, 918-26.

Kind KL, Owens JA, Robinson JS, Quinn KJ, Grant PA, Walton PE, Gilmour RS, Owens PC (1995) Effect of restriction of placental growth on expression of IGFs in fetal sheep: relationship to fetal growth, circulating IGFs and binding proteins. J Endocrinol 146, 2334.

Kwong WY, Wild AE, Roberts P, Willis AC, Fleming TP (2000) Maternal undernutrition during the preimplantation period of rat development causes blastocyst abnormalities and programming of postnatal hypertension. Development 127, 4195-202.

Lane M, Gardner DK (2003) Ammonium induces aberrant blastocyst differentiation, metabolism, $\mathrm{pH}$ regulation, gene expression and subsequently alters fetal development in the mouse. Biol Reprod 69, 1109-17.

Lee ES, Fukui Y, Lee BC, Lim JM, Hwang WS (2004) Promoting effect of amino acids added to a chemically defined medium on blastocyst formation and blastomere proliferation of bovine embryos cultured in vitro. Anim Reprod Sci 84, 257-67.

Lowenstein L, Cantlie G, Ramos O, Brunton L (1966) The incidence and prevention of folate deficiency in a pregnant clinic population. Can Med Assoc J 95, 797-806. 
Maher ER, Brueton LA, et al. (2003) Beckwith-Wiedemann syndrome and assisted reproduction technology (ART). J Med Genet 40, 62-4.

McConnell JM, Petrie L (2004) Mitochondrial DNA turnover occurs during preimplantation development and can be modulated by environmental factors. Reprod Biomed Online 9, 418-24.

McGinnis LK, Albertini DF, Kinsey WH (2007) Localized activation of Src-family protein kinases in the mouse egg. Dev Biol 306, 241-54.

Mitra J, Schultz RM (1996) Regulation of the acquisition of meiotic competence in the mouse: changes in the subcellular localization of cdc2, cyclin B1, cdc25C and wee1, and in the concentration of these proteins and their transcripts. J Cell Sci 109 (Pt 9), 2407-15.

Niemann H, Wrenzycki C (2000) Alterations of expression of developmentally important genes in preimplantation bovine embryos by in vitro culture conditions: implications for subsequent development. Theriogenology 53, 21-34.

Obata Y, Kono T (2002) Maternal primary imprinting is established at a specific time for each gene throughout oocyte growth. J Biol Chem 277, 5285-9.

Orstavik KH, Eiklid K, van der Hagen CB, Spetalen S, Kierulf K, Skjeldal O, Buiting K (2003) Another case of imprinting defect in a girl with Angelman syndrome who was conceived by intracytoplasmic semen injection. Am J Hum Genet 72, 218-9.

Ratnam S, Mertineit C, Ding F, Howell CY, Clarke HJ, Bestor TH, Chaillet JR, Trasler JM (2002) Dynamics of Dnmt1 methyltransferase expression and intracellular localization during oogenesis and preimplantation development. Dev Biol 245, 304-14.

Rinaudo P, Schultz RM (2004) Effects of embryo culture on global pattern of gene expression in preimplantation mouse embryos. Reproduction 128, 301-11.

Rinaudo PF, Giritharan G, Talbi S, Dobson AT, Schultz RM (2006) Effects of oxygen tension on gene expression in preimplantation mouse embryos. Fertil Steril 86 Suppl 4, 1252-65, 1265 e1-36.

Roseboom TJ, van der Meulen JH, Ravelli AC, Osmond C, Barker DJ, Bleker OP (2001) Effects of prenatal exposure to the Dutch famine on adult disease in later life: an overview. Mol Cell Endocrinol 185, 93-8.

Schultz GA, Heyner S (1993) Growth factors in preimplantation mammalian embryos. Oxf Rev Reprod Biol 15, 43-81.

Selwood L, Johnson MH (2006) Trophoblast and hypoblast in the monotreme, marsupial and eutherian mammal: evolution and origins. Bioessays 28, 128-45. 
Sjoblom C, Roberts CT, Wikland M, Robertson SA (2005) Granulocyte-macrophage colony-stimulating factor alleviates adverse consequences of embryo culture on fetal growth trajectory and placental morphogenesis. Endocrinology 146, 2142-53.

Sjoblom C, Wikland M, Robertson SA (1999) Granulocyte-macrophage colonystimulating factor promotes human blastocyst development in vitro. Hum Reprod 14, 3069-76.

Skinner MK (2007) Endocrine disruptors and epigenetic transgenerational disease etiology. Pediatr Res 61, 48R-50R.

Susiarjo M, Hassold TJ, Freeman E, Hunt PA (2007) Bisphenol A exposure in utero disrupts early oogenesis in the mouse. PLoS Genet 3, e5.

Taylor PD, McConnell J, et al. (2005) Impaired glucose homeostasis and mitochondrial abnormalities in offspring of rats fed a fat-rich diet in pregnancy. Am J Physiol Regul Integr Comp Physiol 288, R134-9.

van Engeland M, Weijenberg MP, et al. (2003) Effects of dietary folate and alcohol intake on promoter methylation in sporadic colorectal cancer: the Netherlands cohort study on diet and cancer. Cancer Res 63, 3133-7.

Waddington CH. (1942) The epigenotype. Endeavour 1, 18-20.

Watkins A, Torrens C, Cunningham C, Wilkins A, Gray L, Perry H, Mason M, Fleming TP (2007) Maternal low protein diet during oocyte maturation causes increased systolic blood pressure and abnormal behavior in the mouse. In 'Society for the Study of Reproduction'. San Antonio, TX USA. (Biology of Reproduction)

Young LE, Fernandes K, et al. (2001) Epigenetic change in IGF2R is associated with fetal overgrowth after sheep embryo culture. Nat Genet 27, 153-4.

Yuba-Kubo A, Kubo A, Hata M, Tsukita S (2005) Gene knockout analysis of two gamma-tubulin isoforms in mice. Dev Biol 282, 361-73. 
Table 1. Post fertilization effectors of epigenetic regulation.

\begin{tabular}{|c|c|c|c|c|}
\hline Influencing factor & Location & Time & Action & Reference \\
\hline Maternal nutrition & $\begin{array}{l}\text { Ovary, } \\
\text { oviduct, } \\
\text { uterus }\end{array}$ & $\begin{array}{l}\text { Peri-ovulatory } \\
\rightarrow \text { third trimester }\end{array}$ & $\begin{array}{l}\text { Indirect - fetal } \\
\text { programming } \\
\text { of metabolic } \\
\text { framework. } \\
\text { Direct - DNA } \\
\text { methylation }\end{array}$ & $\begin{array}{l}\text { (van Engeland et } \\
\text { al. 2003) } \\
\text { (Roseboom et al. } \\
\text { 2001) } \\
\text { (Elias et al. } \\
\text { 2005) }\end{array}$ \\
\hline $\begin{array}{l}\text { Organelle } \\
\text { topography }\end{array}$ & Oviduct & Pre-implantation & $\begin{array}{l}\text { Mitochondrial } \\
\text { number and } \\
\text { distribution }\end{array}$ & $\begin{array}{l}\text { (McConnell and } \\
\text { Petrie 2004) } \\
\text { (Taylor et al. } \\
\text { 2005) }\end{array}$ \\
\hline $\begin{array}{l}\text { Cellular } \\
\text { allocation }\end{array}$ & Fertilization & $\begin{array}{l}\text { Fertilization } \rightarrow \\
\text { blastocyst }\end{array}$ & $\begin{array}{l}\text { Changes in } \\
\text { ICM: } \\
\text { trophectoderm } \\
\text { ratio }\end{array}$ & $\begin{array}{l}\text { (Kwong et al. } \\
2000)\end{array}$ \\
\hline $\begin{array}{l}\text { Embryonic } \\
\text { promoting factors }\end{array}$ & $\begin{array}{l}\text { Oviduct, } \\
\text { uterus }\end{array}$ & Pre-implantation & $\begin{array}{l}\text { Growth factors } \\
\text { and buffering } \\
\text { agents to } \\
\text { promote and } \\
\text { protect } \\
\text { embryonic } \\
\text { development }\end{array}$ & $\begin{array}{l}\text { (Sjoblom et al. } \\
\text { 1999) } \\
\text { (Schultz and } \\
\text { Heyner 1993) }\end{array}$ \\
\hline $\begin{array}{l}\text { Embryonic } \\
\text { disrupting factors }\end{array}$ & $\begin{array}{l}\text { Oviduct, } \\
\text { uterus }\end{array}$ & Pre-implantation & $\begin{array}{l}\text { Environmental } \\
\text { toxins, } \\
\text { oxidative } \\
\text { stress, } \\
\text { ammonium }\end{array}$ & $\begin{array}{l}\text { (Susiarjo et al. } \\
\text { 2007) } \\
\text { (Lane and } \\
\text { Gardner 2003) }\end{array}$ \\
\hline $\begin{array}{l}\text { Placental } \\
\text { development }\end{array}$ & & $\begin{array}{l}\text { Implantation } \rightarrow \\
\text { term }\end{array}$ & $\begin{array}{l}\text { Fetal stress } \\
\text { and } \\
\text { undernutrition }\end{array}$ & $\begin{array}{l}\text { (Kind et al. } \\
1995)\end{array}$ \\
\hline
\end{tabular}


Table 2. Hallmarks of oocyte epigenetic competence.

\begin{tabular}{|l|l|}
\hline Target component & Developmental modification \\
\hline Organellar & Composition/Number \\
& Positioning \\
\hline Nuclear & Architecture \\
\hline Cortical & Differentiation \\
& Cortical granules \\
& Microvilli \\
& Actin \\
& MTOCs \\
\hline Zona pellucida & Sperm and cumulus interaction \\
\hline Molecular mediators (mRNA and protein) & Cell cycle factors \\
& Spindle assembly \\
& Polar body extrusion \\
& Localization machinery \\
& Protein synthesis and degradation \\
& Calcium sequestering \\
\hline
\end{tabular}


Table 3. Examples of molecular epigenetic regulators

\begin{tabular}{|c|c|c|c|}
\hline Gene & Function & Impact of loss & KO phenotype \\
\hline cMos (r) & Arrest meiosis (MII) & $\begin{array}{l}\text { Dysregulated first } \\
\text { cell cycle }\end{array}$ & $\begin{array}{l}\text { Pathogenesis } \\
\text { Large PB }\end{array}$ \\
\hline E-Cadherin (p) & Compaction & $\begin{array}{l}\text { Impaired lineage } \\
\text { allocation }\end{array}$ & Arrested morula \\
\hline NMP2 (p) & $\begin{array}{l}\text { Pronuclear } \\
\text { maturation }\end{array}$ & Cell cycle delay & Arrested one cell \\
\hline dMNT1o (p) & $\begin{array}{l}\text { Chromatin } \\
\text { methylation }\end{array}$ & $\begin{array}{l}\text { Modified } \\
\text { methylation }\end{array}$ & Arrested morula \\
\hline Gamma tubulin $(\mathrm{p})$ & Embryonic mitosis & Arrested cell cycle & Arrested morula \\
\hline
\end{tabular}

Specific maternal effect genes are designated based on storage as either mRNA (r) or protein (p). Polar body (PB), meiosis stage 2 (MII). 